
\title{
$\angle$ Research Square \\ Tracking how young baseball pitchers hone the biomechanics of throwing
}

Glenn S. Fleisig

Alek Z. Diffendaffer

Brett Ivey

Kyle T. Aune

Tony Laughlin

Dave Fortenbaugh

Becky Bolt

Wendy Lucas

Kevin D. Moore

Jeffrey R. Dugas

\section{Video Abstract}

Keywords: kinematics kinetics baseball pitching pitcher youth high school adolescent puberty pitching biomechanics athlete stride length lead foot placement trunk separation shoulder rotation shoulder torque elbow torque mechanics American Sports Medicine Institute The American Journal of Sports Medicine

Posted Date: September 20th, 2019

DOI: https://doi.org/10.21203/rs.2.15071/v1

License: (c) (i) This work is licensed under a Creative Commons Attribution 4.0 International License. Read Full License 


\section{Abstract}

Baseball pitchers aren't born knowing how to throw a ball - it takes years of training and practice to hone this ability. Although prior studies have examined how throwing mechanics differ between youth and adult pitchers, no reports have followed the same group of individuals year after year to watch their skills develop. Now, a US-based research team has sequentially tracked young pitchers to identify the biomechanical changes that occur as a pitcher sharpens their skills. The researchers recruited kids from youth baseball leagues who were in their first season playing as pitcher. Each participant was asked to throw 10 full-effort fastballs from the pitching mound to home plate. Before throwing, the pitcher was outfitted with 23 retroreflective markers. The three-dimensional motions of these markers were tracked through 12 synchronized high-speed cameras. Recording the markers' movements provided information related to pitching motion, including the pitcher's stride length and degrees of shoulder and pelvic rotation as well as the torques produced at the elbow and shoulder during a throw. The ball's speed was also recorded via radar. Most participants started the study at 9 years old and were tested annually for 7 consecutive years or until they stopped pitching in baseball leagues. In the end, results were compiled for 35 athletes who pitched for at least 3 years. Various improvements in throwing mechanics were observed during the first few years of pitching. These included a longer stride, more closed front foot position, and increased trunk separation at foot contact. The pitchers also lengthened their arm path due to a better grip on the ball, and showed greater external rotation of the shoulder and forward trunk tilt at ball release. Elbow and shoulder torques also increased, particularly between 13 and 15 years of age. Together, these changes increased ball velocity. These findings suggest that baseball pitchers improve their mechanics during their very first years pitching and begin generating more torque near the age of puberty. Understanding how young pitchers evolve may offer ways to help coach these athletes towards achieving the best results as they age. 